\title{
Recruiting 'hard to reach' parents for health promotion research: experiences from a qualitative study
}

\author{
Louise Tully ${ }^{1 *}$, Eleni Spyreli², Virginia Allen-Walker ${ }^{2}$, Karen Matvienko-Sikar $^{4}$, Sheena McHugh ${ }^{4}$, \\ Jayne Woodside², Michelle C. McKinley², Patricia M. Kearney ${ }^{4}$, Moira Dean ${ }^{3}$, Catherine Hayes ${ }^{5}$, \\ Caroline Heary ${ }^{6}$ and Colette Kelly ${ }^{1}$
}

\begin{abstract}
Objective: Marginalised populations are less likely to take part in health research, and are sometimes considered 'easy to ignore'. We aimed to describe our approach and results of recruiting parents who experience disadvantage, for focus groups exploring infant feeding on the island of Ireland. Upon receiving ethical approval, we implemented recruitment strategies that included building rapport with community organisations through existing networks, targeting specific organisations with information about our aims, and utilising social media groups for parents.

Results: We approached 74 organisations of which 17 helped with recruitment. We recruited 86 parents/carers (one male) for 19 focus groups (15 urban/4 rural). Seventy two percent met at the eligibility criteria. Most participants were recruited through organisations (91\%), and the remainder on social media (9\%). Recruitment barriers included multiple steps, research fatigue, or uncertainty around expectations. Factors such as building rapport, simplifying the recruitment process and being flexible with procedures were facilitators. Despite comprehensive, multi-pronged approaches, the most marginalised parents may not have been reached. Further alternative recruitment strategies are required for recruiting fathers, rural populations, or those without the capacity or opportunity to engage with local services.
\end{abstract}

Keywords: Social Determinants of Health, Research recruitment, Health promotion research, Parenting, Marginalized groups, Hidden populations, Seldom heard voices, Qualitative research

\section{Introduction}

Recruiting a diverse population for qualitative research, who have both experienced the phenomenon of interest and meet specific characteristics, can be challenging, particularly groups that are socially and/or economically disadvantaged, vulnerable or 'hidden' [1,2].

We define 'disadvantaged' as those experiencing socioeconomic disadvantage (i.e. at risk of inequality related

\footnotetext{
*Correspondence: LMTully1@gmail.com

${ }^{1}$ Health Promotion Research Centre, National University of Ireland, Galway, Ireland

Full list of author information is available at the end of the article
}

to employment, education, income, access to healthcare/ resources) and those at risk of social disadvantage (e.g. young parents, lone parents, migrants, those from ethnic minorities, people with disabilities). Those who are vulnerable due to inequality may experience an array of unique circumstances that results in their exclusion from health promotion research, enhancing the issue of 'seldom heard voices' [3] and potentially further exacerbates health inequalities $[4,5]$. The term 'easy to ignore' rather than 'hard to reach' has been used to describe such groups, given these complexities [6], and a need for transparent accounts of researchers' experiences of engaging with such groups for research has been identified [7]. 
We describe our experience of recruiting parents for qualitative health promotion research, and considerations for future recruitment for research aimed at similar populations. We recruited disadvantaged parents, with an infant aged 3-14 months, for focus groups to explore the barriers and facilitators for following infant feeding recommendations, the results of which are published elsewhere $[8,9]$.

\section{Main text}

\section{Methods}

We considered the evidence that social support during parenting predicts successful child outcomes [10-12] alongside the social determinants of health [13], in outlining our eligibility criteria (full criteria in Additional file 1: Table S1).

The research team planned three recruitment strategies (Fig. 1). The first involved recruitment through local community organisations utilising a collaboration agreement that included researchers at a range of academic institutions, with links to the local community, and detailed a commitment to supporting the project. This facilitated additional key recruitment contacts such as local support workers involved directly with groups in deprived areas. Our strategy was to reach out to key gatekeepers within such organisations and, with their permission, provide the study materials to potential participants. We also searched online for key community organisations in the country that engaged specifically with disadvantaged parents, with the aim of employing purposive and snowball sampling. When organisations were identified, we contacted them via email or phone, and provided information about the study. Many of these organisations focused on parenting skills, baby care or support and personal development for single parent families.

For online recruitment of study participants, we shared study information within Facebook support groups for parents and families. The social media strategy included posting an e-flyer with details of the study and the eligibility criteria, asking parents to get in contact via phone, text message or email if they were interested in taking part, on multiple local and national parenting Facebook group pages and Twitter. They were subsequently invited to a focus group if interested.

To overcome documented barriers for attendance at focus groups related to location, timing, childcare responsibilities, format and structure, and cost implications [14], we informed gatekeepers that the focus group would be held at a community venue that is local and familiar to the parents. We also made clear that they would be welcome to bring along their baby, it would be an informal environment with refreshments provided,

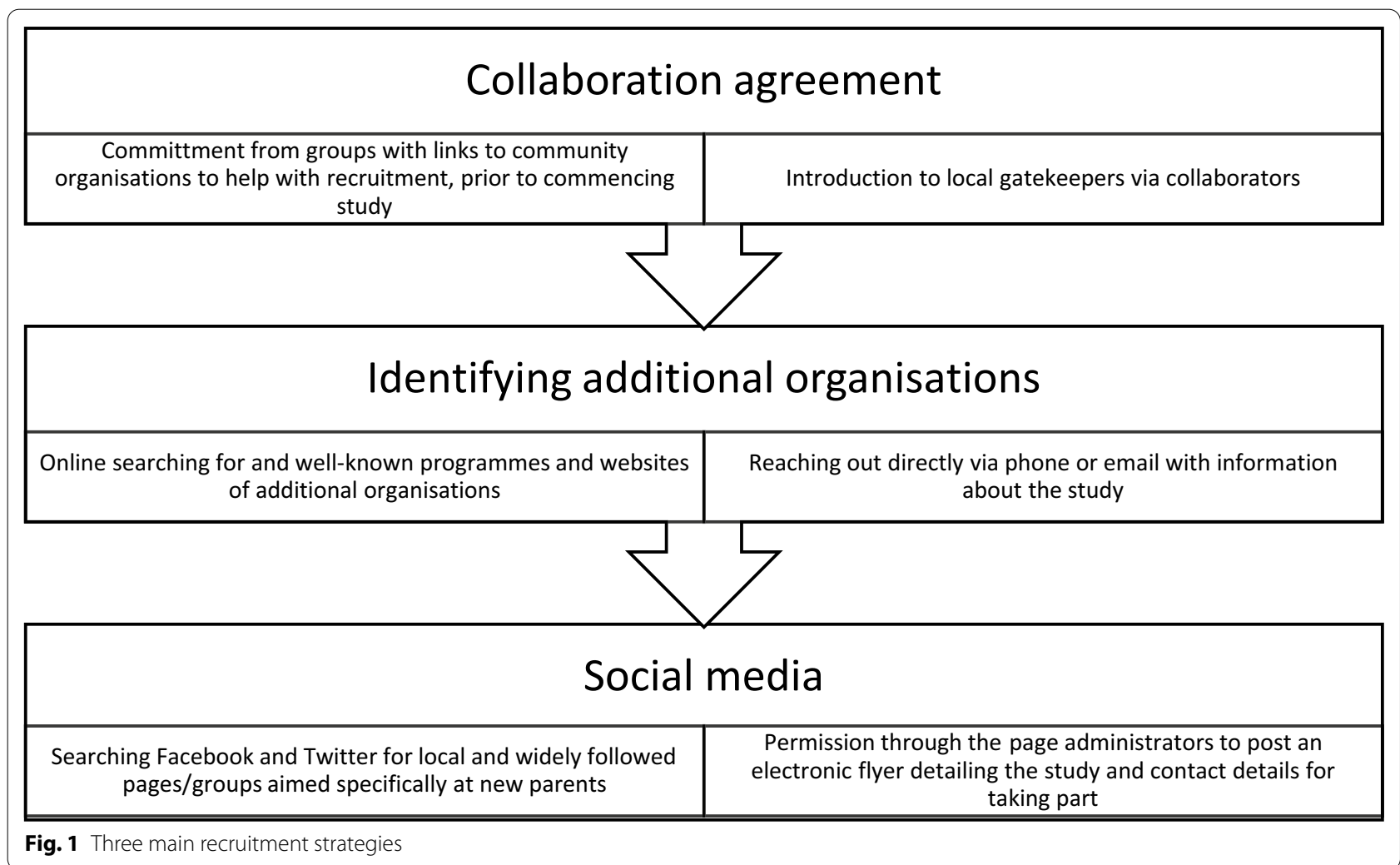


and where needed, participants would be reimbursed for travel costs. We described the data collection as a 'chat' to convey a sense of informality. We also gave a small gratuity voucher $(€ 20 / £ 20$ multi-store gift cards) after focus groups to thank parents for their time and a booklet containing up-to-date recommendations on infant feeding relevant to the local jurisdiction. We gathered demographic and participant characteristic data using questionnaire items from a variety of sources including past censuses for each jurisdiction, and previous studies such as Growing up in Ireland [15]. The questionnaire used in ROI is available to view in supplementary material (Additional file 2), while the focus group topic guide is published elsewhere [16].

\section{Results}

In the ROI, we recruited 46 parents/carers (45 female, one male) for participation in 11 focus groups, of which nine took place in urban and two in rural areas. These took place over seven months. A total of 37 mothers were recruited and took part in $8 \mathrm{NI}$ focus groups, six of which took place in urban areas and two in rural. Focus groups spanned over a 4-month period. There were no fathers/ male carers recruited to the NI sample. In both NI and the ROI, the first focus group served as a pilot (NI $n=5$, ROI $n=4)$, but, due to its wealth of data, contributed to the final sample. Forty organisations were contacted in total by email with follow-up phone calls (if a phone number was available). Of the non-responders $(n=19)$, all had been contacted by email/through a contact form on their website only. A further nine organisations responded to initial communication and expressed being unable to help. Of those who could not help, six provided a reason. Reasons included: perception by the gatekeeper that parents would not be interested/willing, ongoing research involvement in other projects, unsuitable time of year and perception that participants not eligible. Seven organisations proceeded with one or more focus group(s) via their organisations, while one attempted to arrange one but received very little interest. Table 1 conveys the data collection broken down by recruitment strategy, excluding one pilot focus group which consisted of a convenience sample.

In NI, the team contacted 34 organisations by email with follow-up call where possible. Two organisations responded to initial emails but they could not help as their policy didn't allow them to be involved in research. Five asked to be forwarded the study material in case they had any parents interested in taking part, but they did not respond subsequently. Twelve organisations sent positive replies and a visit by a member of the research team was arranged; eight of them proceeded with a focus group.
Table 1 Recruitment for the study based on each strategy employed

\begin{tabular}{ll}
\hline Recruitment strategy & Outcome \\
\hline (i) Collaborator agreement contacts & $\begin{array}{c}\text { Four organisations con- } \\
\text { tacted, one focus group } \\
\text { completed }(n=6, \text { ROI) }\end{array}$ \\
$\begin{array}{c}\text { (ii) Identifying additional relevant organisa- } \\
\text { tions }\end{array}$ & $\begin{array}{l}\text { Seventy organisations } \\
\text { contacted, fifteen focus } \\
\text { groups completed } \\
\text { (iii) Social media }\end{array}$ \\
Two focus groups $(n=8)^{a}$
\end{tabular}

${ }^{a}$ Two participants recruited through social media joined a pre-arranged focus group that took place in a subsequently identified organisation

A breakdown of the sociodemographic characteristics of the participants who attended focus groups in ROI and NI can be seen in Table 2.

Additional file 3: Table S2 provides an overview of the number of indicators of disadvantage met by participants.

Most communication with parents was via the gatekeeper and, when it involved many steps, it was difficult to maintain contact. Moreover, when describing the process to gatekeepers, the additional stage of screening questions for participants (i.e. sending the questionnaire to participants, follow up, determining eligibility and communicating same to parents), may have been too burdensome, perhaps explaining the number who did not get back in contact. Importantly, the possibility of excluding some parents within their group or programme did not appeal to some organisations. Thus, we decided to recruit via invitation to pre-arranged focus group (as opposed to scoping out potential participants for screening and then making arrangements). This meant asking parents to self-screen and allowed for a reduced burden for gatekeepers, enabling parents decide whether to attend or not. While this process risked attendance by parents outside of the target population, it was more practical and time efficient for both the gatekeepers and the research team.

In NI, the recruitment approach was adapted to avoid overlap with another study with the same target population, to avoid research fatigue, which facilitated recruitment. Some challenges included services finishing up for summer, and in one case, a query around governance. Taking note of parents' logistical preferences wherever possible allowed the research team to work around the majority and maximise attendance.

We found that giving as much information as concisely as possible about the study was key when contacting community organisations (gatekeepers) for help with recruitment. Speaking by phone rather than email 
Table 2 Participant characteristics

\begin{tabular}{|c|c|c|c|c|}
\hline Parent characteristic & $\mathrm{N}(\mathrm{ROI})$ & $\%$ (ROI) & $\mathrm{N}(\mathrm{NI})$ & $\%(\mathrm{NI})$ \\
\hline \multicolumn{5}{|l|}{ Place of birth } \\
\hline Ireland/Northern Ireland & 33 & 71.7 & 34 & 91.9 \\
\hline Other part of United Kingdom & 1 & 2.2 & 1 & 2.7 \\
\hline Other European country & 4 & 8.7 & 1 & 2.7 \\
\hline Africa & 6 & 13 & 0 & 0 \\
\hline Asia & 1 & 2.2 & 0 & 0 \\
\hline Australia & 0 & 0 & 1 & 2.7 \\
\hline Not specified & 1 & 2.2 & 0 & 0 \\
\hline \multicolumn{5}{|l|}{ Ethnicity } \\
\hline White & 34 & 73.9 & 36 & 97.3 \\
\hline Irish Traveller ${ }^{\mathrm{a}}$ & 5 & 10.8 & 0 & 0 \\
\hline Black or Black Irish: African & 5 & 10.8 & 1 & 2.7 \\
\hline Any other Black background & 1 & 2.2 & 0 & 0 \\
\hline Asian & 1 & 2.2 & 0 & 0 \\
\hline \multicolumn{5}{|l|}{ Employment } \\
\hline Employed / self-employed & 18 & 39.1 & 26 & 70.3 \\
\hline Unemployed / home duties & 25 & 54.3 & 10 & 27 \\
\hline Long term sickness/disability ${ }^{\mathrm{b}}$ & 1 & 2.2 & 0 & 0 \\
\hline Student $^{2}$ & 2 & 4.3 & 0 & 0 \\
\hline Not specified & 0 & 0 & 1 & 2.7 \\
\hline \multicolumn{5}{|l|}{ Marriage status } \\
\hline Married / cohabiting & 36 & 78.2 & 24 & 64.9 \\
\hline Single & 4 & 8.7 & 10 & 27 \\
\hline Separated / divorced ${ }^{\mathrm{b}}$ & 0 & 0 & 3 & 8.1 \\
\hline Not specified & 6 & 13 & 0 & 0 \\
\hline \multicolumn{5}{|l|}{ Eligibility for benefits } \\
\hline Full medical card ${ }^{b}$ or Healthy Start ${ }^{c}$ & 24 & 52.1 & 16 & 43.2 \\
\hline \multicolumn{5}{|l|}{ Social support } \\
\hline Enough help & 29 & 63 & 30 & 81.1 \\
\hline Not enough help & 8 & 17.4 & 6 & 16.2 \\
\hline No help at all & 3 & 6.5 & 1 & 2.7 \\
\hline
\end{tabular}

${ }^{a}$ An indigenous ethnic minority group

${ }^{\mathrm{b}}$ Asked in ROI only; Full medical card: a means tested entitlement to reduced cost or free medical care for a wide range of services used as an indicator for low income

c Asked in NI only; Healthy Start: a means tested UK government food welfare scheme for low income or at risk families used as an indicator for low income

Some questionnaire items differed slightly in each jurisdiction as they were taken from either the UK or Irish censuses (Additional file 2)

also proved more productive (seen in the high number of non-responders being those contacted by email only), and allowed researchers to build rapport more easily.

Buy-in and interest from gatekeepers were deciding factors in whether or not information about the study would reach parents. It was sometimes clear that gatekeepers felt it important to protect their potentially vulnerable group from what they may have perceived as a risk of feeling inadequate or the perception of being accused of doing something 'wrong.' Programmes more familiar with participating in research were usually more willing to engage. Some gatekeepers sought resources from the research team in the form of information sessions or workshops around infant feeding or child nutrition in return for informing parents about the study, which helped with forging a relationship and a sense of reciprocal input. Arranging groups to coincide with events (such as workshops) already planned for parents helped attendance. Table 3 summarises the barriers to recruitment in this population that we encountered and describes solutions we found and suggests potential solutions for future research.

\section{Discussion}

Our findings demonstrate that using as wide a variety of communication tools was central to successful recruitment, and often direct communication by phone was best for reaching busy community groups. Social networking sites, whilst widely utilised among young people and a well-established recruitment avenue [25], were not a straightforward outlet for recruitment to health promotion research, particularly for capturing a specific target population such as ours. If research budgets allow, it may be worthwhile to pay for targeted advertising on social media, which has been shown as a useful research recruitment tool [26]. Some literature suggests that social media use is not representative of the general population [27] and this further emphasises the need for targeted approaches for recruitment online.

Recruiting participants from deprived populations through community organisations is recommended in the literature [14], and was efficient for accessing large groups of parents. It also added a sense of legitimacy to the study when being pitched to potential participants through someone with whom they were familiar. However, recruiting through such initiatives risks over-burdening gatekeepers and potentially service-users, and in research fatigue [28]. This may help explain, at least partly, the poor response rate to initial contact. Another consideration is that such organisations tend to exist in densely populated areas, and this is reflected in our low number of focus groups in rural areas compared with urban areas. Parents experiencing marginalisation who live rurally may be further isolated by living further from amenities.

\section{Limitations}

We almost certainly encountered missed opportunities to include the voices of those who might not have the capacity or desire to attend community initiatives. Future research should explore additional strategies to 
Table 3 Summary of recruitment challenges we encountered and suggested solutions

\begin{tabular}{|c|c|}
\hline Recruitment challenge & Potential solution \\
\hline $\begin{array}{l}\text { Recruiting insufficient numbers in locality of research institutions and } \\
\text { therefore needing to recruit nationwide }\end{array}$ & $\begin{array}{l}\text { Ensure considerations and resources for travel or alternatively online data } \\
\text { collection are built into grants applications, research protocols and } \\
\text { timelines [17] } \\
\text { Consider inclusion of a Public and Patient Involvement (PPI) panel to advise } \\
\text { all aspects of the study, including recruitment [18] }\end{array}$ \\
\hline $\begin{array}{l}\text { Difficulty adhering to research timelines due to unsuccessful early recruit- } \\
\text { ment efforts }\end{array}$ & $\begin{array}{l}\text { Ensuring flexibility in terms of time and contingency plans, and } \\
\text { Allowing for transcription and data analysis to run concurrently with further } \\
\text { recruitment and data collection [19] }\end{array}$ \\
\hline $\begin{array}{l}\text { Challenges with capturing the attention and interest of gatekeepers dur- } \\
\text { ing initial contact and building rapport }\end{array}$ & $\begin{array}{l}\text { Contact by phone and not email } \\
\text { Utilising existing connections where possible } \\
\text { Providing study information as succinctly as possible } \\
\text { Consider offering resources, data collection relevant to the goals of the } \\
\text { organisation, or expertise [20] (in our case infant feeding workshops/ } \\
\text { information) to allow a sense of reciprocal input }\end{array}$ \\
\hline $\begin{array}{l}\text { Maintaining buy-in from gatekeepers due to the complicated logistics of } \\
\text { carrying out screening questionnaires prior to inviting eligible partici- } \\
\text { pants to a focus group, and the possibility of excluding people }\end{array}$ & $\begin{array}{l}\text { Avoiding too many steps in the process and pre-empting logistical barriers } \\
\text { [20]: consider providing the inclusion criteria with details of pre-arranged } \\
\text { focus groups, allowing participants to self-screen. Demographic question- } \\
\text { naires during data collection can be used to measure eligibility }\end{array}$ \\
\hline $\begin{array}{l}\text { Difficulty recruiting via social media compared with other routes: difficult } \\
\text { to find appropriate groups/pages to target, with correct demographic } \\
\text { and sufficient reach }\end{array}$ & $\begin{array}{l}\text { Consider whether sponsored advertisements on social media may be help- } \\
\text { ful, and build this into research budget } \\
\text { Approaching group/page administrators to post material the group to } \\
\text { engender sense of legitimacy and relevance [21] } \\
\text { Identifying social media 'champions' who could assist in online dissemina- } \\
\text { tion [22] }\end{array}$ \\
\hline $\begin{array}{l}\text { In areas with limited organisations to contact for recruitment (such as } \\
\mathrm{NI} \text { ), there was a risk of research fatigue among those who are regularly } \\
\text { approached for research }\end{array}$ & $\begin{array}{l}\text { Consider whether collaboration with another research study to combine } \\
\text { data collection for answering multiple research questions is feasible, while } \\
\text { carefully assessing burden on the participant }\end{array}$ \\
\hline $\begin{array}{l}\text { Seasonality of services and participant availability e.g. parent group clos- } \\
\text { ing for the summer }\end{array}$ & $\begin{array}{l}\text { Make a list of organisations and their schedules early on so approaching } \\
\text { those who are seasonal can be prioritised [23] }\end{array}$ \\
\hline $\begin{array}{l}\text { Approaches used successfully recruited female parents/carers but did not } \\
\text { result in recruitment of fathers/male carers }\end{array}$ & $\begin{array}{l}\text { Additional and specific recruitment efforts for recruiting male parents } \\
\text { should be researched and planned in advance, where fathers/male carers } \\
\text { are explicitly invited [24] }\end{array}$ \\
\hline
\end{tabular}

include those from marginalised populations who are not in touch with local organisations, whilst being mindful of ethical considerations. Further, almost a third of participants did not meet eligibility criteria, resulting from our amendment to have potential participants self-screen and asking gatekeepers to invite participants to a prearranged focus group. This reduced our ability to manage how eligibility criteria were communicated to parents.

No participants availed of travel cost reimbursement. It is possible that some may not have had the means to pay for transport up front, or that asking for reimbursement risked feelings of shame or stigma. A consideration for future studies may be to offer to arrange transport in advance.

For the most part, we used proxy measures for indicators of disadvantage such as eligibility for income support, however this was in order to reduce the burden on participants. Among the research team, there was consensus that developing a questionnaire item to assess income was potentially intrusive and unnecessary, when eligibility for a medical card (in ROI)/Healthy
Start (NI) was a good indicator. For some of the other indicators however, the relationship was less clear. We asked people to report their ethnicity and country of birth using items from the Irish census, however these alone do not give a clear picture of disadvantage.

With the exception of one male participant, this study did not capture father-driven data. This is an important factor to consider for future research, as family dynamics are extremely complex and all perspectives are important [29]. The help-seeking behaviours of male caregivers may differ, in that the services utilised by mothers/female caregivers may not be accessible or attractive to fathers for a variety of reasons [30].

In summary, key facilitators for recruitment were building rapport with gatekeepers, simplifying the recruitment process to reduce the burden for gatekeepers, and being flexible by amending the recruitment strategy in response to barriers encountered throughout the process. Specific recruitment strategies aimed at fathers and rural parents should be considered. 


\section{Abbreviations}

ROI: Republic of Ireland; NI: Northern Ireland.

\section{Supplementary Information}

The online version contains supplementary material available at https://doi. org/10.1186/s13104-021-05653-1.

\section{Additional file 1: Table S1. Participant eligibility criteria.}

Additional file 2: Participant demographic questionnaire.

Additional file 3: Table S2.Number of criteria associated with disadvantage met among participants.

\section{Acknowledgements}

The authors wish to acknowledge the organisations, collaborators and individuals who provided invaluable advice, guidance and support throughout the planning, data collection and dissemination for this research study. We particularly wish to thank the gatekeepers who considered our request for support with recruitment, and all of the parents who gave their time.

\section{Authors' contributions}

Conceptualisation: CK, PK, JW, C.Hayes, CH, and SMc Methodology: CK, PK, JW, LT and SMc. Investigation: LT, ES and VAW Resources: CK, JW, MC., MD Data Curation: LT, VAW and ES Writing-original draft: LT, ES, VAW, CK Writingreview and editing: LT, ES, VAW, CK, KMS, SMC, C. Hayes, CH, MD, MCM, and PK Supervision: CK, JW, MD and MCM Project Administration: LT, CK and VAW. Funding Acquisition: CK, PK, JW, SMc. All authors read and approved the final manuscript.

\section{Funding}

The research described in this article was funded by Safefood, the Food Safety Promotion Board of Ireland, Grant No: 11-2015.

\section{Availability of data and materials}

Not applicable.

\section{Declarations}

\section{Ethics approval and consent to participate}

This study was conducted in accordance with the Declaration of Helsinki. Ethical approval was obtained from National University of Ireland Galway (ref: 16/ May/10) and Queen's University Belfast (ref: 16/40) research ethics committees. Written informed consent for participation was received by all participants.

\section{Consent for publication}

Not applicable.

\section{Competing interests}

The authors have no conflicts of interest to declare.

\begin{abstract}
Author details
${ }^{1}$ Health Promotion Research Centre, National University of Ireland, Galway, Ireland. ${ }^{2}$ Centre for Public Health, School of Medicine, Dentistry and Biomedical Sciences, Queens University Belfast, Belfast, UK. ${ }^{3}$ School of Biological Sciences, Institute for Global Food Security, Queens University Belfast, Belfast, UK. ${ }^{4}$ School of Public Health, University College Cork, Cork, Ireland. ${ }^{5}$ School of Medicine, Trinity College Dublin, Dublin, Ireland. ${ }^{6}$ School of Psychology, National University of Ireland, Galway, Ireland.
\end{abstract}

Received: 16 February 2021 Accepted: 10 June 2021 Published online: 21 July 2021
References

1. Mirick RG. Challenges in recruiting parents to participate in child welfare research: Implications for study design and research practice. Child Fam Soc Work. 2016;21(4):484-91.

2. Ellard-Gray A, Jeffrey NK, Choubak M, Crann SE. Finding the hidden participant: Solutions for recruiting hidden, hard-to-reach, and vulnerable populations. Int J Qual Methods. 2015:14(5):1609406915621420.

3. Lowrie E, Tyrrell-Smith R. Using a Community-Engaged Research (CEnR) approach to develop and pilot a photo grid method to gain insights into early child health and development in a socio-economic disadvantaged community. Res Involv Engagement. 2017;3(1):29.

4. Richards T. Partnership with patients. Patients want more than simply information; they need involvement too. BMJ. 1998:316:85. https://doi. org/10.1136/bmj.316.7125.85.

5. Marmot M. The health gap: the challenge of an unequal world. Lancet. 2015:386(10011):2442-4.

6. Lightbody R. "Hard to reach'or 'easy to ignore'? Promoting equality in community engagement. 2017. Edinburgh: What Works Scotland [online] Available at: http://whatworksscotland.ac.uk/publications/hard-to-reachor-easy-to-ignore-promoting-equality-in-community-engagement-evide nce-review/. Accessed 18 June 2021

7. Rockliffe L, Chorley AJ, Marlow LA, Forster AS. It's hard to reach the "hard-to-reach": the challenges of recruiting people who do not access preventative healthcare services into interview studies. Int J Qual Stud Health Well Being. 2018;13(1):1479582.

8. Tully L, Allen-Walker V, Spyreli E, McHugh S, Woodside J, Kearney P, et al. Solid advice: complementary feeding experiences among disadvantaged parents in two countries. Maternal Child Nutri. 2019;15:12801.

9. Spyreli E, McKinley MC, Allen-Walker V, Tully L, Woodside JV, Kelly C, et al. "The one time you have control over what they eat": a qualitative exploration of mothers' practices to establish healthy eating behaviours during weaning. Nutrients. 2019;11(3):562.

10. Ferguson KM. Social capital and children's wellbeing: a critical synthesis of the international social capital literature. Int J Soc Welf. 2006;15(1):2-18.

11. Huang CY, Costeines J, Kaufman JS, Ayala C. Parenting stress, social support, and depression for ethnic minority adolescent mothers: Impact on child development. J Child Fam Stud. 2014;23(2):255-62.

12. Kana'laupuni SM, Donato KM, Thompson-Colon T, Stainback M. Counting on kin: Social networks, social support, and child health status. Soc Forces. 2005;83(3):1137-64.

13. Dahlgren G, Whitehead M. Policies and strategies to promote social equity in health. Stockholm: Institute for future studies. 1991:1-69. [online] Available at: http://repositori.uji.es/xmlui/bitstream/handle/ 10234/187797/GoeranD_Policies_and_strategies_to_promote_social_ equity_in_health.pdf?sequence=1. Accessed 18 June 2021.

14. Bonevski B, Randell M, Paul C, Chapman K, Twyman L, Bryant J, et al. Reaching the hard-to-reach: a systematic review of strategies for improving health and medical research with socially disadvantaged groups. BMC Med Res Methodol. 2014;14(1):42.

15. Castro PD, Kearney J. A study of early complementary feeding determinants in the Republic of Ireland based on a cross-sectional analysis of the Growing Up in Ireland infant cohort. Public Health Nutr. 2015:18(2):292-302

16. Tully L, Allen-Walker V, Spyreli E, McHugh S, Woodside J, Kearney P, et al. Solid advice: complementary feeding experiences and use of quidance among disadvantaged parents in two countries. Maternal Child Nutr. 2019;15:12801.

17. Wilkerson JM, lantaffi A, Grey JA, Bockting WO, Rosser BRS. Recommendations for internet-based qualitative health research with hard-to-reach populations. Qual Health Res. 2014;24(4):561-74.

18. Morgan H, Thomson G, Crossland N, Dykes F, Hoddinott PJ. Combining PPI with qualitative research to engage 'harder-to-reach'populations: service user groups as co-applicants on a platform study for a trial. Res Involvement Engagement. 2016;2(1):1-26.

19. Yu H, Abdullah A, Saat RM. Overcoming time and ethical constraints in the qualitative data collection process: A case of information literacy research. J Librariansh Inf Sci. 2014;46(3):243-57.

20. Schelbe L, Chanmugam A, Moses T, Saltzburg S, Williams LR, Letendre J. Youth participation in qualitative research: Challenges and possibilities. Qual Soc Work. 2014;14(4):504-21. 
21. Marks A, Wilkes L, Blythe S, Griffiths R. A novice researcher's reflection on recruiting participants for qualitative research. Nurse Res. 2017;25(2):34.

22. Coiera E. Social networks, social media, and social diseases. BMJ (Clin Res ed). 2013. https://doi.org/10.1136/bmj.f3007.

23. Halcomb EJ, Gholizadeh L, DiGiacomo M, Phillips J, Davidson PM. Literature review: considerations in undertaking focus group research with culturally and linguistically diverse groups. J Clin Nurs. 2007;16(6):1000-11.

24. Davison KK, Charles JN, Khandpur N, Nelson TJ. Fathers' perceived reasons for their underrepresentation in child health research and strategies to increase their involvement. Matern Child Health J. 2017;21(2):267-74.

25. Fenner Y, Garland SM, Moore EE, Jayasinghe Y, Fletcher A, Tabrizi SN, et al. Web-based recruiting for health research using a social networking site: an exploratory study. J Medical Internet Res. 2012;14(1):20.

26. Thornton L, Batterham PJ, Fassnacht DB, Kay-Lambkin F, Calear AL, Hunt S. Recruiting for health, medical or psychosocial research using Facebook: systematic review. Internet Interv. 2016:4:72-81.
27. Mellon J, Prosser C. Twitter and Facebook are not representative of the general population: Political attitudes and demographics of British social media users. Research Politics. 2017:4(3):2053168017720008.

28. Clark T. We're over-researched here!' exploring accounts of research fatigue within qualitative research engagements. Sociology. 2008;42(5):953-70.

29. Cabrera NJ, Volling BL, Barr R. Fathers are parents, too! Widening the lens on parenting for children's development. Child Development Perspectives. 2018;12(3):152-7.

30. Fletcher RJ, StGeorge JM. Men's help-seeking in the context of family separation. Adv Ment Health. 2010;9(1):49-62.

\section{Publisher's Note}

Springer Nature remains neutral with regard to jurisdictional claims in published maps and institutional affiliations.
Ready to submit your research? Choose BMC and benefit from:

- fast, convenient online submission

- thorough peer review by experienced researchers in your field

- rapid publication on acceptance

- support for research data, including large and complex data types

- gold Open Access which fosters wider collaboration and increased citations

- maximum visibility for your research: over 100M website views per year

At BMC, research is always in progress.

Learn more biomedcentral.com/submissions 